\title{
Mortality Due to Cardiovascular Disease in Women During the Reproductive Age (15 to 49 years), in the State of São Paulo, Brazil, from 1991 to 1995
}

\author{
N agib Haddad, Maria Barbosa da Silva
}

São Paulo, SP - Brazil

\begin{abstract}
Objective - To describe mortality due to cardiovascular diseases in women during the reproductive age (15 to 49 years) in the state of São Paulo, Brazil, from 1991 to 1995.
\end{abstract}

Methods - A list of all deaths and their underlying causes, coded according to the International Classification of Diseases, $9^{\text {th }}$ revision, multiple causes of death, and estimates of the female population according to age groups were provided by the SEADE Foundation. Specific coefficients for 100 thousand women for each year as well as the medians of these coefficients related to 5 years, and the percentage of death by subgroups were calculated.

Results - Cerebrovascular diseases have the highest coefficients (14.24 for 100 thousand females), followed by ischemic heart disease (7.37), other heart diseases (6.39), hypertensive disease (3.03), chronic rheumatic heart disease (1.58), pulmonary vascular diseases (1.29), and active rheumatic fever (0.05). Systemic arterial hypertension, as an associated cause, occurred in $55.3 \%$ to $57.8 \%$ of all the deaths due to intracerebral hemorrhage and in $30.4 \%$ to $30.8 \%$ due to subarachnoid hemorrhage.

Conclusion - The significance of cerebrovascular diseases, coronary artery disease, and systemic arterial hypertension as causes of mortality suggests the need to emphasize preventive actions for young women who have the potential to reproduce to avoid possible complications in future pregnancies, and premature mortality.

Keywords: female mortality, cardiovascular diseases, cerebrovascular diseases.

Instituto Dante Pazzanese de Cardiologia - Secretaria de Estado da Saúde de São Paulo - Brazil

Mailing address: Nagib Haddad - Instituto Dante Pazzanese de Cardiologia - Av. Dr. Dante Pazzanese, 500 - 5ํ- 04012-180 - São Paulo, SP - Brazil
The significance of cardiovascular diseases as causes of morbidity and mortality in females has been reported in the last few years mainly for postmenopausal women ${ }^{1-4}$.

Lotufo ${ }^{4}$ compared mortality rates according to age, in persons ranging from 45 to 64 years old during the period from 1984 to 1987 in eight Brazilian capitals with similar statistics in European countries and in the United States. He found that heart diseases in these Brazilian cities have a high mortality rate, which is similar or even higher than that observed in those countries, especially among females.

However, few studies have focused on young women in their reproductive age, that is, before menopause ${ }^{5-8}$.

Haddad and Silva ${ }^{8}$ studied the causes of death and maternal mortality in women 15 - to 49 years old in the state of São Paulo during the period from 1991 to 1995 . They noticed that-in younger women ( 15 to 34 years old) underlying causes of death were frequently among those described in chapter XVII of the International Classification of Diseases, $9^{\text {th }}$ revision (CID-9) ${ }^{9}$, as well as lesions and poisoning, but in 35- to 49-year-old-women, diseases described in chapters II and VII of the CID-9 (neoplasms and circulatory system, respectively) became the most frequent causes. Lesions and poisoning occupied a third position in 35- to 44-yearold women and the fifth position in 45- to 49-year-old women. Respiratory diseases, reported in chapter VIII, were present in all studied ages of the five most frequent underlying causes of death, occupying the third position in the 45 to 49 year age group.

Another observation was that diseases reported in chapter I of CID -infectious and parasitic diseases- in all age groups occupied the seventh or eighth position in the descending range of the median coefficients of mortality in five years. The great decrease in the incidence of these diseases, together with the increased incidence of chronic diseases and diseases of external causes, support the idea that an epidemiological transition has occurred in São Paulo secondary to the demographic, socioeconomic, and sanitary changes that have emerged in the last decades. The same authors also noted that among the main causes of maternal 
mortality, complications during pregnancies (CID-9: 640648) comprise $60.7 \%$ of all deaths related to maternal deaths and, among these causes, hypertension as a complication of pregnancy, puerperium, and delivery was the most frequent (21.9\%). Other maternal problems followed (19.7\%), and of these $61.5 \%$ were related to other cardiovascular diseases.

These findings led the present study to focus on the mortality rate specific for cardiovascular diseases. The underlying causes of death reported in chapter VII of the CID9 -cardiovascular diseases- that occurred in 15- to 49-yearold women during the period from 1991 to 1995 in the state of São Paulo, Brazil, are presented and discussed.

\section{Methods}

The Sistema Estadual de Análise de Dados Foundation (SEADE) provided a list of all deaths of 15- to 49-yearold women that occurred from 1991 to 1995 in the state of São Paulo. The list included all personal characteristics and other information included in the death certificate, as well as a classification of underlying causes of death coded in the four-digit-number-format used in the CID- $9^{9}$. Multiple causes and also estimates of the female population according to different ages for the same period of time, were also provided. For the classification of basic causes of death, the SEADE Foundation used the Automated Classification of Medical Entities (ACME) ${ }^{10}$. The population estimates in the years between periods when census had been performed were obtained according to the growth observed in the period from 1991 to 1996 , taking into consideration the population that was included in the census from 1991 to 1996 and the net population change calculated from death and live birth statistics from the SEADE Foundation.

Specific coefficients of mortality were calculated by dividing the number of deaths due to a specific cause in a specific age group by the female population in the same age group for the same year and then multiplying by 100 thousand.

For comparison of a specific mortality coefficient during the period from 1991 to 1995 -according to age groups, the median coefficient for a five-year period was calculated by placing the five coefficients in an increasing order and calculating the median values.

Some comparisons of specific underlying causes of deaths were calculated using the percentage in relation to the total subgroups in the CID-9.

Data from floppy disks, the total calculation of underlying causes of death according to age groups, and the calculation of the respective mortality coefficient were performed using the SPSS for Windows Version 6.0 ${ }^{11}$.

\section{Results}

From 1991 to $1995,71,041$ deaths occurred in 15- to 49year-old women. The main underlying causes of death were cardiovascular diseases $(22.8 \%)$, neoplasms (17.6\%), lesions and poisoning (16.6\%), and respiratory diseases (7.4\%).
Infectious and parasitic diseases represented an underlying cause in only $4.5 \%$ of all deaths, occupying the eighth position in descending order. Other causes represented $31.1 \%$ of all deaths.

Figure 1 shows the median coefficient during the period from 1991 to 1995 for 100 thousand women of all underlying causes of death in chapters I, II, VII, VIII, and XVII of the CID-9, where it can be observed that lesions and poisoning show a coefficient that does not change very much with older age, but that lesions and poisoning are number one in 15- to 34-year-old women. After 35 years of age, cardiovascular diseases and neoplasms have coefficients that progressively increase in an almost geometric fashion. In the 45- to 49-year-old group, respiratory diseases occupies a third position. It can also be noted that infectious and parasitic diseases have a relatively low coefficient with a small tendency to increase with age.

The specific coefficient for the several underlying causes of deaths due to cardiovascular diseases did not show any tendency in relation to time during the short period of five years of the study. The median coefficients during this period were then calculated (table I)

In this table, it can be observed that in 15- to 49-yearold women- cerebrovascular diseases had the highest coefficients (14.24 per 100 thousand women), followed by ischemic heart diseases (7.37), other heart diseases (6.39), hypertensive disease (3.03), chronic rheumatic heart diseases (1.58), and pulmonary vascular diseases (1.29). Active rheumatic fever had the lowest coefficient (0.05).

Figure 2 shows the median mortality coefficient for the most frequent cerebrovascular diseases during the study period according to different ages. Analyzing the figure, one can see that subarachnoid hemorrhage and intracerebral hemorrhage have a low mortality coefficient in the young age group that increases in a similar degree until the age of 30 to 34 is reached. At this point, intracerebral hemorrhage becomes more frequent, reaching the value of 18.16 per 100

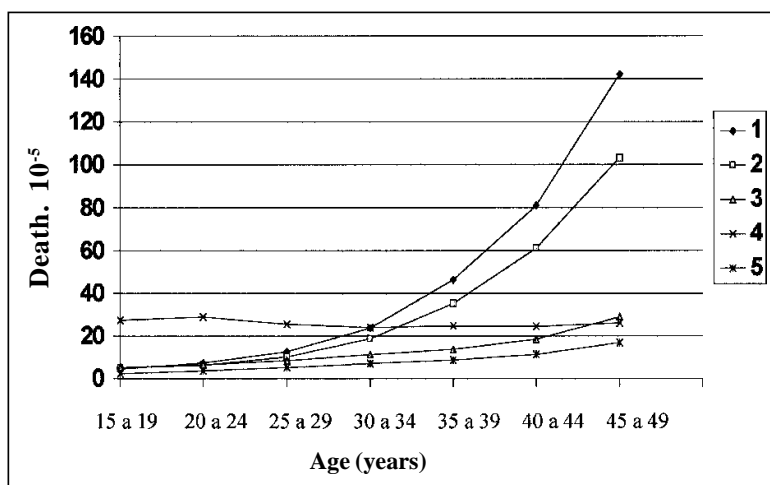

$1=$ circulatory system diseases $2=$ Neoplasms $3=$ respiratory diseases 4= Injury and poisomimg $5=$ Infectious and parasitic diseases

Fig. 1 - Female mortality in 15- to 49-year-old women due to cardiovascular diseases, neoplasms, diseases of the respiratory system, lesions and poisoning, and infectious and parasitic diseases in the state of São Paulo, Brazil, from 1991 to 1995, according to age groups (median coefficient in five years per 100 thousand women) 


\begin{tabular}{|c|c|c|c|c|c|c|c|c|}
\hline \multicolumn{9}{|c|}{$\begin{array}{l}\text { Table I - Diseases of the cardiovascular system as the underlying } \\
\text { cause of death in women ranging from } 15 \text { to } 49 \text { years of age in the } \\
\text { state of São Paulo, Brazil, presented by age group during the period } \\
\text { from } 1991 \text { to } 1995 \text { (median coefficient per } 100 \text { thousand women) }\end{array}$} \\
\hline \multirow{3}{*}{$\begin{array}{l}\text { Code } \\
\text { CID-9* }\end{array}$} & \multirow{3}{*}{$\begin{array}{c}15 \text { a } \\
19\end{array}$} & \multicolumn{5}{|c|}{ Age (years) } & \multirow{2}{*}{\multicolumn{2}{|c|}{$\begin{array}{ll} & \text { Total } \\
45 \mathrm{a} & 15 \mathrm{a}\end{array}$}} \\
\hline & & $20 \mathrm{a}$ & $25 \mathrm{a}$ & $30 \mathrm{a}$ & $35 \mathrm{a}$ & $40 \mathrm{a}$ & & \\
\hline & & 24 & 29 & 34 & 39 & 44 & 49 & 49 \\
\hline $390-392$ & 0.06 & 0.00 & 0.07 & 0.00 & 0.00 & 0.09 & 0.11 & 0.05 \\
\hline $393-398$ & 0.46 & 1.02 & 0.80 & $1, .20$ & 1.67 & 3.20 & 4.39 & 1.58 \\
\hline $401-405$ & 0.24 & 0.76 & 0.93 & 1.73 & 3.77 & 7.26 & 12.84 & 3.03 \\
\hline $410-414$ & 0.33 & 0.52 & 1.74 & 3.66 & 9.00 & 16.56 & 36.45 & 7.37 \\
\hline $415-417$ & 0.26 & 0.63 & 0.93 & 0.83 & 1.52 & 2.23 & 4.22 & 1.29 \\
\hline $420-429$ & 1.34 & 2.18 & 3.09 & 4.81 & 7.78 & 12.65 & 23.74 & 6.39 \\
\hline $430-438$ & 1.21 & 2.04 & 4.07 & 10.70 & 20.73 & 34.63 & 52.70 & 14.24 \\
\hline $440-448$ & 0.07 & 0.20 & 0.46 & 0.56 & 1.32 & 2.32 & 4.87 & 1.02 \\
\hline $451-459$ & 0.07 & 0.20 & 0.34 & 0.28 & 0.48 & 0.84 & 2.02 & 0.49 \\
\hline \multicolumn{4}{|c|}{ * 390-392: Acute rheumatic fever } & $\begin{array}{l}415 \\
\text { dise }\end{array}$ & $\begin{array}{l}-417: \mathrm{Pu} \\
\text { ase }\end{array}$ & ulmonar & y vascul & \\
\hline \multirow{3}{*}{\multicolumn{4}{|c|}{$\begin{array}{l}\text { 393-398: Chronic rheumatic } \\
\text { heart disease } \\
\text { 401-405: Hypertensive disease } \\
\text { 410-414: Ischemic heart disease }\end{array}$}} & & $\begin{array}{l}-429: \mathrm{O} \\
\text { ases }\end{array}$ & ther hea & & \\
\hline & & & & 430 & -438: Ce & erebrova & ascular $\mathrm{c}$ & diseases \\
\hline & & & & & $\begin{array}{l}-448: \mathrm{Di} \\
\text { riolae, a }\end{array}$ & $\begin{array}{l}\text { iseases o } \\
\text { nd capil }\end{array}$ & $\begin{array}{l}\text { of the ar } \\
\text { laries }\end{array}$ & Irteries, \\
\hline \multicolumn{9}{|c|}{$\begin{array}{l}\text { 451-459: Diseases of veins, lymphatics and other disease of the circulatory } \\
\text { system }\end{array}$} \\
\hline
\end{tabular}

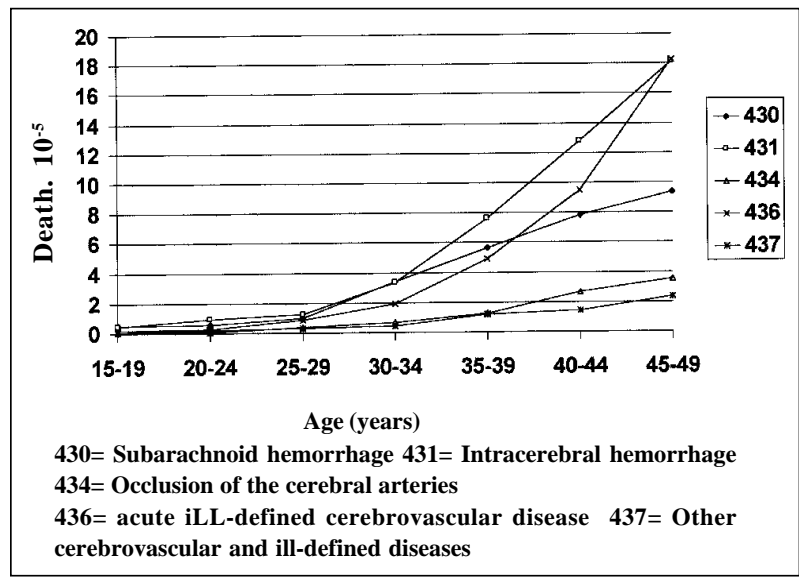

Fig. 2 - Female mortality in 15- to 49-year-old women due to subarachnoid hemorrhage, intracerebral hemorrhage, occlusion of the cerebral arteries, acute ill-defined cerebrovascular disease, and other cerebrovascular and ill-defined diseases in the state of São Paulo, Brazil, from 1991 to 1995 according to age groups (median coefficients in five years per 100 thousand women).

thousand women in the age group between 45 and 49 years old. Poorly defined acute cerebrovascular diseases also show a coefficient that gradually increases with age, with higher increases at 35 to 39 years of age and reaching the value of 18.29 per 100 thousand women at age group of 44 to 49 years, when a higher coefficient than intracerebral hemorrhage is observed. Occlusions of the cerebral arteries and other cerebrovascular diseases, as well as the poorly defined ones, have much lower coefficients, and they also gradually increase with age, reaching values of 3.54 and 2.39 per 100 thousand women, respectively, in the 45 to 49 age group. Deaths caused by intracerebral and subara- chnoid hemorrhages were used to investigate the association with hypertension using coded multiple causes. Hypertensive disease was an associated cause in 55.3 to $57.8 \%$ of the deaths due to intracerebral hemorrhage and in 30.4 to $30.8 \%$ due to subarachnoid hemorrhage.

Table II shows the mortality associated with specific cardiovascular, non-cerebrovascular basic causes, which had the highest median coefficient according to age. Myocardial infarction has a low coefficient in young women but, after the age group of 30 to 34 years, this coefficient progressively increases with age, reaching 31.47 per 100 thousand women at the age group of 45 to 49 years. Heart failure as an underlying cause of death has coefficients that

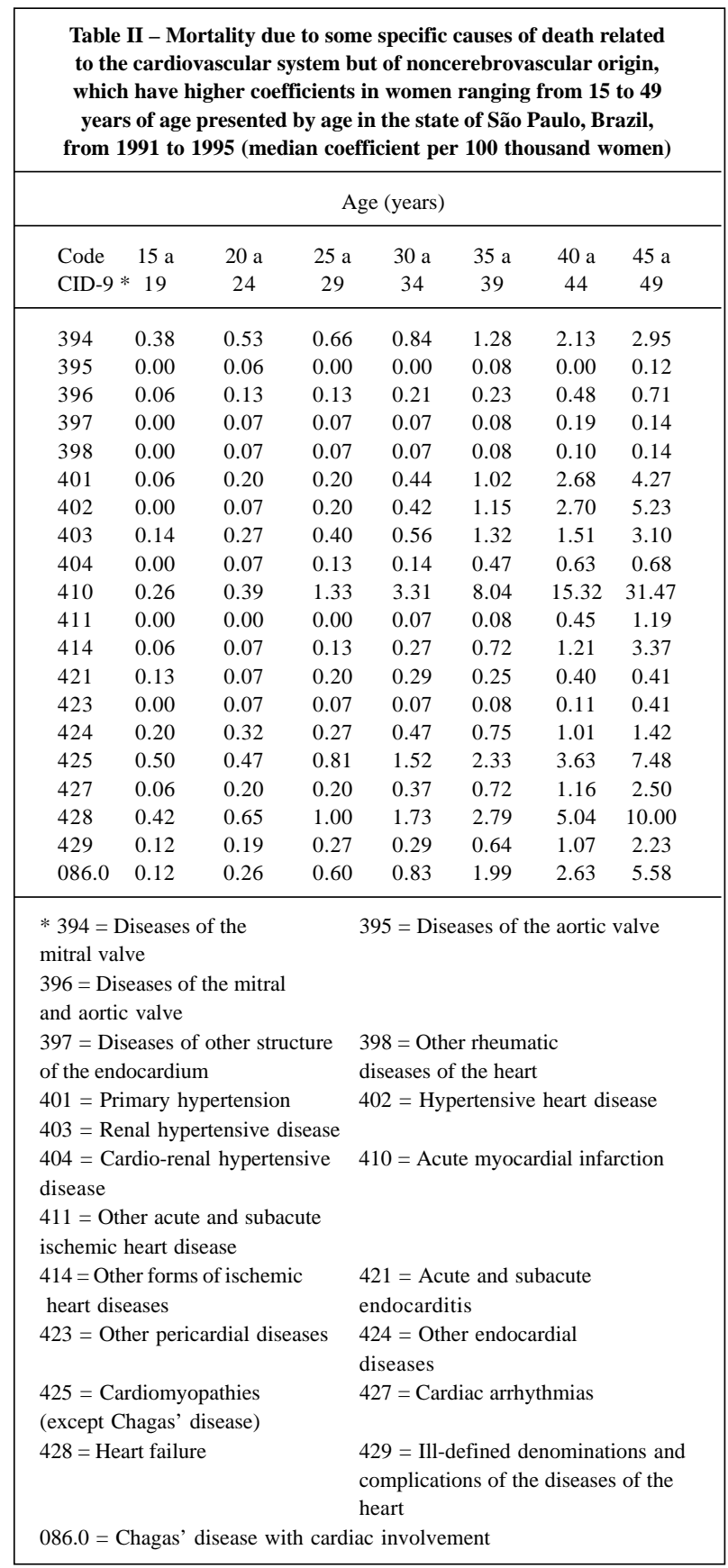


stand out from the other causes and increase with age, reaching 10.00 per 100 thousand women in the oldest group in this study. The group of cardiomyopathy had coefficients that went up to 0.50 to 7.48 per 100 thousand women from the first to the last studied group. As for the different forms of hypertensive disease, hypertensive heart disease had the highest coefficient, followed by essential hypertension, hypertensive renal disease, and cardiorenal hypertensive disease in the oldest studied age groups. Chronic rheumatic valvar diseases of the mitral valve were the most frequent valvar heart diseases, followed by mitral and aortic stenosis and regurgitation, and by isolated aortic valve disease, with coefficients that mildly increased with age and infeccious endocarditis had little increase with age.

The pulmonary vascular diseases that had the highest mortality coefficient were pulmonary embolism (CID-9: 415.1), primary pulmonary hypertension (CID-9: 416.0) and nonspecified pulmonary heart disease (CID-9: 416.9), which includes chronic cor pulmonale. Coefficients increased gradually with age, from 0.18 to 3.07 in pulmonary embolism, from 0.06 to 0.34 in primary pulmonary hypertension, and from 0.06 to 0.52 in nonspecific cor pulmonale between the youngest and the oldest studied group. Because Chagas' heart disease was classified as a trypanosomiasis, together with other infectious and parasitic diseases, the underlying cause 086.0 cited in chapter I of the CID- 9 was used for Chagas' disease with heart involvement, with coefficients that increased with age from 0.12 at 15 to 19 years to 5.58 per 100 thousand women at 45 to 49 years of age (table II).

\section{Discussion}

Mortality data obtained from the analysis of death certificates have limitations related to inadequate filling out of underlying or associated causes in the event. However, studies using this database are very useful in the sense that they provide important information for the overall knowledge of underlying causes of mortality according to individual characteristics, their evolution in time, and their distribution in space. The great decrease in the relative significance of infectious and parasitic diseases, followed by the increase in cardiovascular diseases and neoplasms, with coefficients that increase with age, and the high mortality rate due to external causes, especially in younger females (fig. 1) support the epidemiological transition that occurred in the state of São Paulo in the last decades due to demographic, socioeconomic and sanitary changes in this period of time. Analysis of Table I shows the relative significance of the cerebrovascular diseases among the cardiovascular diseases. Carvalheiro and Manço ${ }^{5}$, in Ribeirão Preto, Brazil, also found a higher frequency of these diseases in 15- to 49year-old women from 1985 to 1989 . Lolio et al. ${ }^{6}$, in the county of São Paulo in 1986, also showed a higher proportion of cerebrovascular diseases among circulatory diseases. However, Katz et al. ${ }^{7}$, in Boston, USA, found much higher coefficients for heart diseases than for cerebrovascular diseases in 15- to 44-year-old women from 1980 to 1989 . Lolio and
Laurenti ${ }^{12}$, in a study of the mortality trends due to cerebrovascular diseases in adults over 20 years of age in the county of São Paulo from 1950 to 1981 found a decrease in the coefficients between 1970 and 1981 for both sexes after the age of 50. Lotufo ${ }^{13}$ and Lotufo and Lolio ${ }^{14}$, studying the mortality trends in cardiovascular diseases in the state of São Paulo during the period from 1970 to 1989 found a decrease in the coefficients of the cerebrovascular diseases during the 20 years of their study. This decrease was more accentuated in the decade from 1980 to 1989 , but only for older people (older than 60 years for man and than 40 years for women).

In developed countries, in the last few decades, a decrease in mortality due to ischemic heart disease and to cerebrovascular disease has been observed in both sexes, with a higher decrease in cerebrovascular diseases ${ }^{13-15}$. This decrease may be related to a probable better prevention of risk factors, to more accurate diagnostic methods, to early treatment, to the use of new therapeutic modalities, to better medical care, or to a possible change in the natural history of these diseases.

Truelsen et al. ${ }^{16}$ described a gradual decrease in mortality due to cerebrovascular diseases after the second half of the 1970 decade for both sexes in New Zealand. They also showed at the same period a decrease in the specific mortality from subarachnoid hemorrhage, with higher coefficients in women than in men.

Some authors have described cerebral strokes, such as intracerebral hemorrhage, subarachnoid hemorrhage, and the occlusion of arteries by a thrombus or embolus, as complications of pregnancy and puerperium ${ }^{17,18}$.

Subarachnoid hemorrhage is usually secondary to rupture of an aneurysm or to intracranial arteriovenous malformations. Because it is a congenital disease, its rupture may be associated with some risk factors, such as hypertension and smoking ${ }^{13,17}$.

Occlusion of a cerebral artery was not very frequent in the present study, because this disease becomes more prevalent with older age, in women older than 50 years who were not included in this investigation.

An increase in the mortality coefficient related to acute cerebrovascular diseases that are poorly defined according to age (fig. 2) may be due to the fact that it is more difficult to reach a precise diagnosis in the age group where strokes are more frequent.

Because hypertension is a well-known risk factor for intracerebral and even subarachnoid hemorrhage, we selected cases with these diagnoses as the underlying cause of death and searched for associated causes of death using multiplecauses codes related to hypertensive disease (CID-9: 401 a 405). Among cases of intracerebral hemorrhage, we found $55.3 \%$ to $57.8 \%$ of associated hypertensive disease and, among cases of subarachnoid hemorrhage, $30.4 \%$ to $30.8 \%$ of this association. These findings emphasize the significance of systemic arterial hypertension as a risk factor for cerebrovascular diseases and the necessity for a better control in hypertensive women to avoid not only these but also other cardiovascular diseases. Ischemic heart disease was the second 
most common disease, with $88 \%$ of the cases presenting as acute myocardial infarction (CID-9:410). Table II shows that myocardial infarction has mortality coefficients that increase with age and reach 31.47 per 100 thousand women in the 45 to 49 age group. Several studies have shown the increasing significance of ischemic heart disease as a cause of morbidity and mortality in women ${ }^{1-4,13,19,20}$. However, the great majority of these studies are restricted to older, postmenopausal patients, with a discussion about the possibly protective effect of hormone administration in the prevention of ischemic disease in these patients.

The present study emphasizes the importance of acute myocardial infarction as a cause of death in relatively young women before menopause when their female hormones are still within normal levels. Socioeconomic, demographic, and cultural factors among females have changed in the last decades, as these women's participation in the market place increases and exposes them to risk factors for atherosclerosis of the coronary arteries, previously known in the male population, such as obesity, hypertension, high cholesterol levels, sedentary life, stress and, most of all, smoking, which is significantly increasing, especially among younger females.

Heart failure (CID-9: 428), the end stage for diseases of different etiologies, also has coefficients that increase with age and perhaps represent a late stage of medical care and do not allow for a specific etiological diagnosis.

Among patients in the hypertensive disease group, essential hypertension, hypertensive heart disease, and renal hypertensive disease emerge as important causes of death among older women and, probably, their coefficients must be underestimated due to the lack of information on death certificates or to the criteria used to classify the basic causes of death established by the CID-9. Chronic rheumatic valvar diseases still represent an important health problem in underdeveloped countries, and they appear with some degree of importance in the present study as an underlying cause of death, expressing the incidence of rheumatic fever in previous decades. Chagas' disease with heart involvement, in spite of the effective prophylaxis in the transmission of the disease by Triatoma in the last decades in the state of São Paulo, still emerged as an underlying cause of death in relatively young females, probably due to the migration of patients from other States where prophylaxis is not adequate yet, or due to casual transmission by blood transfusion, or even due to a rare congenital transmission.

Women in the 15 to 49 year age range constitute a group that can potentially generate children. That is why it is important to better understand morbidity and mortality in this age group and then adopt preventive actions that will not only avoid the occurrence of the previously described diseases outside pregnancy but also preserve good health in future mothers and fetuses. For those who have severe heart diseases that may increase the morbidity and mortality risk for both mother and fetus, family planning and occasional recommendations of anticonception methods may be applied ${ }^{21}$.

\section{Acknowledgements}

We thank the Sistema Estadual de Análise de Dados Foundation (SEADE) for providing the data used in the present study.

\section{References}

1. Wilson PWF, Garrison RJ, Castelli WP. Postmenopausal estrogen use, cigarette smoking, and cardiovascular morbidity in women over 50. N Engl J Med 1985; 313: $1038-43$.

2. Stampfer MJ, Colditz GA, Willet WC, et al. Postmenopausal estrogen therapy and cardiovascular disease: ten years follow up from the Nurses' Health Study. N Engl J Med 1991; 325: 756-62.

3. Wenger NK, Speroff L, Packard B. Cardiovascular health and disease in women. N Engl J Med 1993; 329: 247-56.

4. Lotufo PA. Mortalidade precoce por doenças do coração no Brasil. Comparação com outros países. Arq Bras Cardiol 1998; 70: 321-5.

5. Carvalheiro CDG, Manço ARX. Mortalidade feminina no período reprodutivo em localidade urbana da região sudeste do Brasil. Evolução nos últimos 20 anos. Rev Saúde Pública 1992; 26: 239-45.

6. Lolio CA, Laurenti R, Buchala CM, Santo AH, Mello Jorge MHP. Mortalidade de mulheres em idade fértil no município de São Paulo (Brasil), 1986. III- Mortes por diferentes causas: doenças cardiovasculares. Rev Saúde Pública 1991; 25: 37-40.

7. Katz ME, Holmes MD, Power KL, Wise PH. Mortality rates among15-to-44-years old women in Boston: looking beyond reproductive status. Am J Publ Health 1995; 85: 1135-8.

8. Haddad N, Silva MB. Mortalidade feminina em idade reprodutiva, no Estado de São Paulo, Brasil, 1991 a 1995: Causas básicas de óbito e mortalidade materna. Rev Saúde Pública 2000; 34: 64-70.

9. Organização Mundial da Saúde. Manual da Classificação Estatística Internacional de Doenças, Lesões e Causas de Óbito; $9^{a}$ Revisão, 1975. São Paulo, Centro da OMS para Classificação de Doenças em Português, 1980.

10. Giraldelli BW, Saad PM. Considerações sobre a implantação no Estado de São Paulo do Sistema Automático de Classificação de Causas de Morte. Inf Demogr 1984; 13: 137-59.
11. Norusis MJ. SPSS for Windows. Release 6.0. Chicago, SPSS Inc., 1993.

12. Lolio CA, Laurenti R. Tendência da mortalidade por doenças cerebrovasculares em adultos maiores de 20 anos de idade no município de São Paulo (Brasil), 1950 a 1981. Rev Saúde Pública 1986; 20: 343-6.

13. Lotufo PA. As doenças cardiovasculares no Brasil: Estudo de caso da tendência da mortalidade no Estado de São Paulo 1970-89. São Paulo, 1993 (Dissertação de Mestrado). São Paulo: Faculdade de Saúde Pública da Universidade de São Paulo, 1993.

14. Lotufo PA, Lolio CA. Tendência da mortalidade por doença cerebrovascular no Estado de São Paulo: 1970 a 1989. Arq Neuropsiquiatr 1993; 51 : 441-6.

15. Lolio CA, Souza JMP, Laurenti R. Decline in cardiovascular disease mortality in the city of S.Paulo, Brazil, 1970 to 1983. Rev Saúde Pública 1986; 20: 454-64.

16. Truelsen T, Bonita R, Duncan J, Anderson NE, Mee E. Changes in subarachnoid hemorrhage mortality, incidence and case fatality in New Zealand between 19811983 and 1991-1993. Stroke 1998; 29: 2298-303.

17. Knepper LE, Giuliani MJ. Cerebrovascular disease in women. Cardiology 1995; 86: 339-48.

18. Simolke GA, Cox SM, Cunningham FG.Cerebrovascular accidents complicating pregnancy and the puerperium. Obstetrics \& Gynecology 1991; 78: 37-42.

19. Corrao JM, Becker RC, Ockene IS, Hamilton GA. Coronary heart disease risk factors in women. Cardiology 1990; 77(suppl. 2): 8-24.

20. Kuhn FE, Rackley CE. Coronary artery disease in women. Risk factors, evaluation, treatment and prevention. Arch Intern Med 1993; 153: 2626-34.

21. Sociedade Brasileira de Cardiologia. Consenso Brasileiro de Cardiopatia e Gravidez. Diretrizes da Sociedade Brasileira de Cardiologia para Gravidez e Planejamento Familiar da Mulher Portadora de Cardiopatia. Arq Bras Cardiol 1999; 72(supl III): 21-26. 